\title{
CABELOS COMO EXTENSÕES RELAÇÕES PROTÉTICAS, MATERIALIDADE E AGÊNCIA NA ESTÉTICA FUNK CARIOCA
}

Mylene Mizrahi (UFRJ)

Ao focalizar a estética corporal produzida para facilitar o entrar e sair de diferentes espaços sociais do Rio de Janeiro, argumenta-se que a "a vida social dos objetos" só pode ser considerada se a qualidade de agência for conciliada com a possibilidade que os objetos materiais encerram de ter seu sentido manipulado. É a partir dessa dupla possibilidade que poderemos então falar em uma rede causal formada por humanos e não humanos, ambos causadores de eventos sem, contudo, perder seus estatutos ontológicos diferenciais. Defenderemos, à luz do perspectivismo ameríndio e a partir de uma discussão sobre a mimésis, que os sujeitos são empoderados pelos objetos e que a aparência mais do que a interioridade é central para as interações sociais, como se dão no ambiente urbano brasileiro.

BELEZA, CORPO, OBJETOS MATERIAIS, ESPAÇO URBANO, RIO DE JANEIRO.

MIZRAHI, Mylene. Cabelos como extensões: relações protéticas, materialidade e agência na estética funk carioca. Textos escolhidos de cultura e arte populares, Rio de Janeiro, v.9, n.2, p. 137157, nov. 2012. 


\section{HAIR AS EXTENSIONS \\ PROSTHETIC RELATIONS, MATERIALITY AND AGENCY IN THE CARIOCA FUNK AESTHETICS}

Mylene Mizrahi (UFRJ)

By focusing on the bodily aesthetic produced to facilitate mobility in and out of different social spaces in Rio de Janeiro, it is argued that "the social life of objects" can only be considered if the quality of agency is reconciled with the possibility that objects may have their meaning manipulated. It is from this double possibility that we can speak of a causal network formed by humans and nonhumans, both triggering events, but without losing their ontological status differentials. We argue, in light of Amerindian perspectivism and from a mimetic discussion, that subjects are empowered by objects and that appearance - more than interiority - is central to social interactions, as they happen in the Brazilian urban environment.

BEAUTY, BODY, MATERIAL OBJECTS, URBAN SPACE, RIO DE JANEIRO.

MIZRAHI, Mylene. Cabelos como extensões: relações protéticas, materialidade e agência na estética funk carioca. Textos escolhidos de cultura e arte populares, Rio de Janeiro, v.9, n.2, p. 137157, nov. 2012. 
O racismo no Brasil é muitas vezes descrito como silencioso, pouco evidente. Esse aspecto que define um racismo à brasileira vem sendo destacado por diferentes produções das ciências sociais no país ou por aquelas feitas a partir de pesquisa empírica aqui conduzida. Esse silêncio, por sua vez, nos remete a discursos outros, não orais, na expressão de preconceitos raciais e clivagens de classe. No Rio de Janeiro, a aparência de uma pessoa é forte componente das relações sociais, de modo que apreciações relativas à raça e à cor são pouco verbalizadas em determinados contextos sociais e podem ser mais bem apreendidas por meio dos discursos estéticos. São elaboradas através da música, da beleza, das imagens e dos objetos, de modo que as estéticas do corpo e a cultura material envolvidas em processos de autoapresentação dos sujeitos oferecem ponto de entrada privilegiado para a problematização das dinâmicas que regem a cultura brasileira de modo amplo. As interações concretas e tradicionalmente subsumidas por categorias como "raça" e "classe social" emergirão da escolha em relação ao adorno adequado a ser portado e do julgamento do gosto. A aparência surge, assim, como elemento potencialmente facilitador da circulação no espaço urbano.

Este artigo possui dois objetivos fundamentais, que surgem permeados por importante vinculação entre beleza e poder aquisitivo. Um deles concerne a fazer emergir uma lógica da prótese governando o montar e o desmontar da beleza em universo recortado por um movimento musical urbano e mais próprio às classe populares do Rio de Janeiro. O outro diz respeito à evidenciação do corpo como instância agentiva de suas escolhas. Nesse sentido, não basta assumir o ponto de vista do corpo, sendo necessário tomá-lo como criativo, do mesmo modo como fazemos com a mente. O corpo é sujeito de suas escolhas. Acompanhamos a manipulação de símbolos tal como feita pelo sujeito criativo funk, de modo que, veremos, não é preciso ser artista no sentido estrito do termo para possuir a habilidade de dominar o significado das representações. Se, entretanto, em termos de operações lógicas e mentais o exercício apresenta continuidade com a criação musical, o lócus de sua execução muda, e, em vez de o resultado surgir em músicas e suas letras ou em imagens verbais e virtuais, ele é materializado no e pelo corpo. O exercício dá a ver a impossibilidade de considerar uma cisão entre corpo e mente.

Nosso argumento emerge de etnografia permeada por discussão teórica pertinente à cultura material e que possui como guia os cabelos femininos. Observamos os objetos materiais articulando e refazendo o social, no contexto de um trabalho de campo desenvolvido a partir da rede de relações de um cantor de funk carioca, Mr. Catra. Os sujeitos constantes da referida etnografia 
são mais propriamente as mulheres que cercam o núcleo familiar do artista. Problematizamos o lugar que a aparência detém para as relações sociais travadas no Rio de Janeiro, com os cabelos articulando o ir e vir de distintos espaços sociais e geográficos.

\section{A PUJANÇA DOS CABELOS}

Os cabelos sempre estiveram presentes nos momentos que antecedem a festa, como possibilidade da transformação necessária para a entrada em sua esfera. Ainda que eles sejam posteriormente carregados para onde quer que seu dono vá, é sempre na imanência da festa que são desencadeadas as elaborações estéticas que os envolvem. A primeira vez em que notei seu poder transformador foi em Tina, como chamarei a moça que trabalhava na casa de Sílvia, a mulher de Mr. Catra. Sílvia viera buscar-me para irmos ao baile do Tuiuti, uma favela na Zona Norte da cidade. Entrei pela porta de trás do carro e sentei-me ao lado de Sílvia, Tábata e outra moça, que não reconheci. Alguns instantes depois, olho novamente para a moça ali sentada e nela reconheço Tina, mas uma Tina absolutamente diferente da que eu conhecera alguns dias antes, quando vestia bermuda, camiseta e uma touca de tricô na cabeça que deixava apenas a franja de seu curto cabelo à mostra, parecendo um menino. Nessa noite ela trajava um vestido vermelho e trazia seus cabelos negros alongados (Figura 1).

Os cabelos retornaram de modo ostensivo nas vésperas do novo ano de 2008, que eram também anteriores ao show de gravação do DVD de Catra. Eu chegara à casa da família Catra para mais uma visita. Junto à grande mesa que fica em um dos cantos da varanda estava sentada Tina, de cabeça baixa, com seus cabelos sendo manipulados por Taninha, a "Taninha do MegaHair", que coloca as "extensões" na cabeça das "passistas da Mangueira", as dançarinas da escola de samba da favela de mesmo nome. Enquanto Tina tinha as mechas de seus cabelos alongadas, sentamo-nos Sílvia e eu em um banco ao lado e conversamos sobre assuntos diferentes, entre eles os cabelos black, usado por algumas atrizes brasileiras, estilo que Sílvia não aprecia. Ao mesmo tempo, ela reclamava dos cabelos da filha pequena que, ao deixar a piscina, tinha-os armados e desalinhados, diferentemente do usual, quando os traz meticulosamente penteados e presos, em rabo de cavalo, maria-chiquinha ou chuquinhas várias.

Foi uma tarde interessante, pois, com os cabelos, emergiu o tema da circulação pela cidade e do preconceito racial, mas de modo implícito, como costumeiro, e de maneira indireta - sem relacionar os cabelos delas a sua 


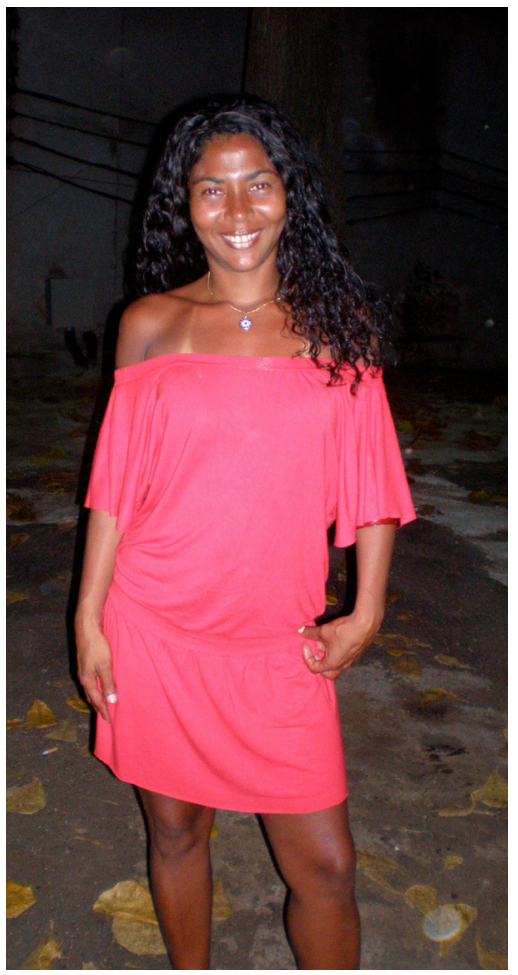

\section{Figura 1: A transformação para a esfera da festa Foto de Mylene Mizrahi}

circulação, mas observando o modo como minha aparência era facilitadora de minha mobilidade, por sua vez intensificada por meu carro.

A pujança que possuem os cabelos no ambiente em que eu pesquisava se revelou de fato para mim, entretanto, em uma terceira ocasião e relacionou novamente a festa, em dois momentos distintos. Dessa vez envolvia Cíntia, a comadre do casal que eu sempre pensei ser branca mas que, como ela me diria, não era branca. Era da "cor que os gringos gostam", diferença que ela me apontou ainda mais claramente quando, em um Natal, eu a presenteei com um gloss, e ela reclamou de sua coloração. Eu já entendera que moças com a "boca preta" não gostam de brilhos labiais escuros, mas os lábios de Cíntia eram, ao meu olhar, claros. Para que eu entendesse melhor a que se referia, ela levantou seus lábios para que eu visse em sua gengiva que eles não eram claros como eu poderia pensar. Cíntia, como nenhuma outra das mulheres com as quais interagi em campo, manipula a ambiguidade de sua aparência para entrar e sair de espaços da cidade.

Chegamos à casa de shows Fundição Progresso, na Lapa, Centro da cidade - bairro que se tornou conhecido como zona de confluência de distintas "tribos" e classes sociais - para a apresentação de Mr. Catra, logo a seguir. Sílvia sobe apressadamente as escadas do camarim em busca de um toalete. Resolvemos fazer o mesmo, mas achamos mais prático entrar em um sanitário ainda no andar térreo. Já tendo saído, através da porta entreaberta observo Cíntia se olhando no espelho. Ela fala que não gosta de si com o cabelo "daquele jeito", "enroladinho". Taíssa, prima de Sílvia, diz que gosta do visual de Cíntia, que, entretanto, continua a se olhar ao espelho e, fazendo cara de desgosto, reafirma, também por meio de palavras, que não aprecia a imagem que vê. 


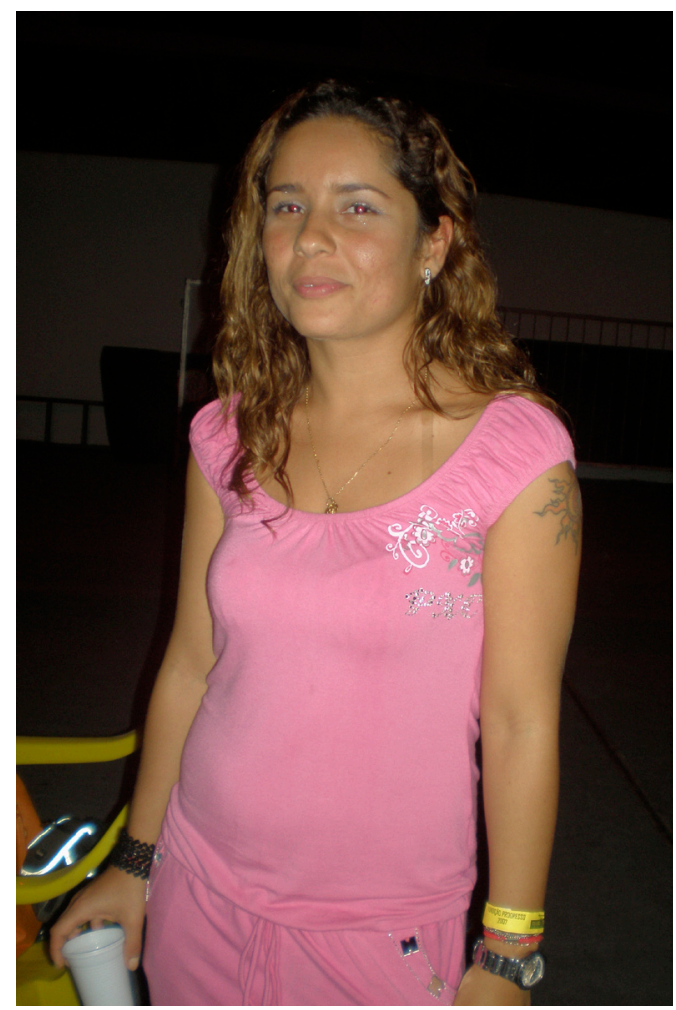

Figura 2: O estilo Funk Foto de Mylene Mizrahi

Cíntia já me dissera, em outras ocasiões, que não lhe agrada usar seus cabelos anelados, e, pensando em outra ocasião que a encontrara de tal modo produzida que não a pude reconhecer, com cabelos lisíssimos e loiríssimos, e a pele dourada, pergunto-Ihe por que viera então com o cabelo daquele modo. Ela me olha, com ar blasé, e diz que é porque veio "representando". Acho certa graça em seu comentário e dou um riso seco. Ela me olha novamente e diz "é verdade", parecendo comunicar que não havia do que se rir ali.

Cíntia, uma mulher com cerca de 30 anos, mignon, de pele clara, que ela já definiu como "encardida", pernas grossas e cintura fina, vestia um microvestido em malha rosa, ajustado ao corpo, com manguinhas curtas levemente franzidas e adornado por aplicações localizadas, feitas por cristal, pequenos quadrados de espelho e ainda uma pequena estampa prateada (Figura 2). A grife da roupa, PXC, assim como a recorrência dos "brilhos" e a modelagem ajustada, é ícone do gosto e do estilo indumentário funk. A PXC é marca de roupa há muito bastante popular entre os funkeiros, e a presença do "brilho" é hoje o grande traço do jeito de vestir em voga entre as meninas no Baile, como antes foi a "calça de moletom stretch" (MIzRAHI, 2006; 2010), que abordarei adiante. Por outro lado, quando encontrei Cíntia com seus cabelos "pranchados", na noite de gravação do DVD de Catra, ela vestia roupa de ares cosmopolitas. Igualmente curto, seu vestido era do tipo tomara que caia e baloné: bufante e esvoaçante, solto no corpo e preso às coxas por uma barra larga, na mesma viscolycra que compunha a peça de roupa (Figura 3). 
Figura 3: O estilo global Foto de Mylene Mizrahi

Essa malha, fina, fria e mole, era estampada em motivo abstrato de ares psicodélicos. Cíntia, através de suas roupas e cabelos, nos comunica sua habilidade na manipulação de representações.

Quando deseja ou Ihe é conveniente, se apresenta como funkeira. E, quando

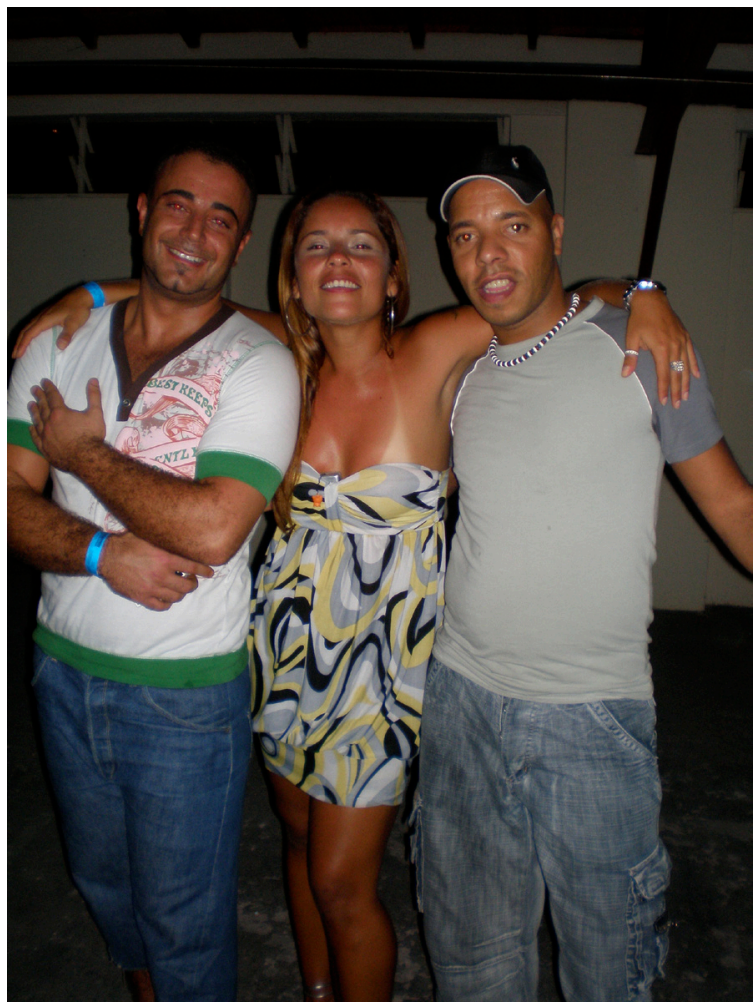
quer, pode também passar por uma jetsetter internacional. O "representar" é categoria nativa. Alguém "representa legal" quando manda de modo convincente sua mensagem, ao falar em nome dos seus. A expressão pode ser usada, por exemplo, para aferir a performance de um MC - "ele representou legal" - mas também a performance de uma pessoa em seu processo de autoapresentação.

Cíntia sabe bem como escapar às representações, às cristalizações que elas podem produzir, e nessas horas escolhe um visual mais cosmopolita, mudando estilos indumentários, cabelo e maquiagem. Com isso, ela não está comunicando apenas como é hábil na manipulação de símbolos, mas como domina os códigos estéticos de diferentes ambientes, potencializando seu trânsito entre eles. Esta é uma habilidade [skill] partilhada pelos sujeitos criativos funk, artistas ou não, permitindo fluidez na passagem entre diferentes mundos sociais.

Depois de mais uma tarde em Vargem Grande dirijo de volta para casa e Cíntia retorna comigo "para a Sul", a Zona Sul do Rio de Janeiro, área privilegiada da cidade e onde fica a favela em que ela mora. Cíntia faz algumas 


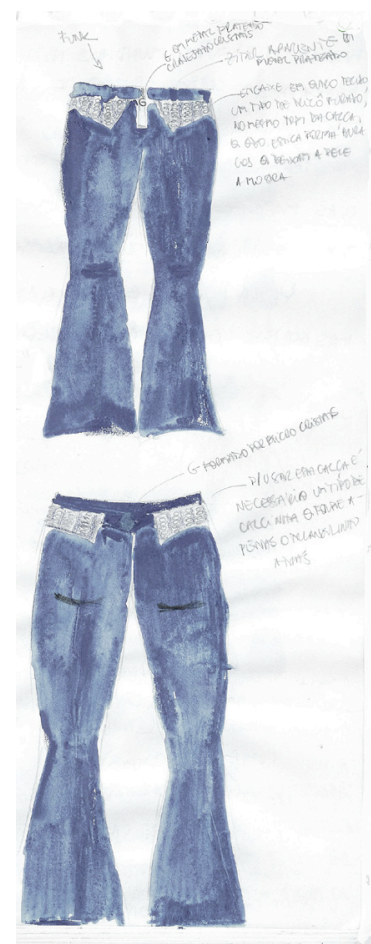

Figura 4: "“Calça de moletom stretch" llustração de Mylene Mizrahi

ligações. Está em busca de companhia para o show de Catra, a que assistirá mais tarde na Katmandu, boate localizada na porção ipanemense do entorno da Lagoa Rodrigo de Freitas, também na Zona Sul. Primeiro ela telefona para Bebel, que está cansada e quer dormir cedo. Liga então para outra amiga, que diz estar "loiríssima", mas também não quer sair. Cíntia pergunta-Ihe se fez "tudo isso" (descolorir os cabelos) "para ficar em casa?!". A moça diz que não fez escova nos cabelos, e que "o problema é que está loira, e loira de cabelo duro não dá". Cíntia desliga o telefone e reclama da justificativa da amiga para sair, parecendo achar excessiva sua preocupação. Mas em seguida comenta que mais tarde fará uma escova com a "tiazinha lá do morro", uma senhora que atende na favela em que mora.

\section{CABELOS COMO EXTENSÕES}

Cíntia, diz Sílvia, "é uma piranha": é abençoada por cabelos que não precisam de extensões. Cíntia dá um sorriso de consentimento, parecendo concordar que ela é mesmo agraciada com uma dádiva divina. Enfatiza, porém, que seu cabelo para chegar ao ponto em que chegou precisou passar por "vários processos". Em compensação, ela "está como?; só jogando". "Jogar" os cabelos significa tê-los longos a ponto de, ao virar a cabeça de um lado para outro, eles acompanharem o movimento, se deslocando na direção oposta. Por isso Cíntia é como se abençoada, pois, apesar de ter feito "várias progressivas", tem hoje seu cabelo, que era "miojinho", com textura suficiente para estar longo e ainda possuir versatilidade para os momentos em que o quer anelado ou liso.

A consideração se justifica pois nem sempre os cabelos resistem aos tratamentos relaxantes que permitem a cabelos como os de Cíntia crescer, anelar ou ser alisados - de tão finos, não resistem à "química" e "quebram". Os fios partem ao longo do processo. É isto que os faz "não crescerem" ou demandarem muito tempo para que isso ocorra: a pouca resistência aos produtos para alisar os cabelos e "relaxar" os cachos. Se gostassem de 
penteados no estilo afro, seus cabelos cresceriam. E, em vez de os usarem "baixinhos" e "vazios", como gostam, os trariam "armados", "cheios" ou trançados. Mulheres como Sílvia, Tábata e Tina recorrem, então, às extensões capilares.

Encontrei a cabeleireira Taninha em três diferentes ocasiões. Na primeira vez ela fazia os cabelos de Tina, como mencionei. As duas outras vezes também antecederam festas e marcaram minha saída e meu retorno a campo: quando parti para fazer a bolsa-sanduíche em Londres, nas vésperas de mais um ano-novo, e quando fiz minha primeira visita à casa ao voltar de viagem, nas vésperas de mais uma festa do bicheiro amigo da família. Os cabelos definitivamente precisaram ser olhados com cuidado, mas eu vinha de um campo em que eles não me pareceram tão relevantes. Muito diferentemente do que aqui ocorreu, eles não clamaram por minha atenção.

Minha investigação de mestrado (MIZRAHI, 2006) transcorreu majoritariamente em um determinado baile funk. Ainda que eu tenha acompanhado as moças e rapazes em incursões para compras de roupas ou em visitas ao barbeiro, o foco principal da pesquisa foi a produção para a festa, estando esta circunscrita a um contexto específico e a um evento particular, e o trânsito por diferentes ambientes sociais da cidade não foi problematizado.

A marca estilística feminina que emergiu do conjunto indumentário que arrolei foi a "calça de moletom stretch", que ficou conhecida na mídia como "calça da gang" (Figura 4). De fato eu já cheguei ao Baile interessada em problematizar os resultados de pesquisa anterior (MIZRAHI, 2003), que seguiu o processo de ressignificação da "calça da gang" na mídia, que por sua vez atribuía o sucesso da peça de roupa a sua capacidade de "dar bunda" à usuária. A calça, segundo o discurso midiático, produziria por si mesma um corpo. No Baile, como constatei, o relevante não era a marca de seu fabricante, mas a materialidade de seu tecido, que emprestava seu nome à categoria englobante que designou o estilo: "calça de moletom stretch". As propriedades físicas do objeto, em sua interação com o corpo e seus atributos culturais, fizeram com que as moças do Baile dele se apropriassem e criassem assim um estilo, através do sentido que lhe atribuíram por meio de seu uso na festa. A calça não concedia atributos corporais, mas os realçava. Por esse motivo, moças de corpo magro e poucas curvas elegiam peças de roupas alternativas. A calça que vazou para o "alto gosto" era criação delas e não produção individual resultante de uma suposta fórmula mágica encontrada para gerar belos corpos.

O estilo em questão referia-se a uma calça elástica como as de ginástica, mas de tecido que, após ser tinturado e lavado, adquiria o aspecto do denim, 
simulando assim uma calça jeans. Entretanto, essas calças femininas eram feitas não do índigo blue, o tecido plano que dá origem ao jeans e pode adquirir alguma elasticidade ao ser mesclado à lycra, mas de malha - tecido circular que já é em si elástico - que misturada à lycra fica superelástica. Isso torna a calça superconfortável para a dança, que era, em última instância, o que movia os jovens ali. Além disso, o moletom stretch, o tecido que compõe o estilo, apesar de ser malha, era suficientemente resistente para receber as ações embelezadoras que a fizeram peça de roupa apropriada para a esfera da festa, com elaborações barrocas como bordados, cristais, perfurações, tachas de metal, encaixes de outros tecidos, rendas e telas. Por outro lado, essa malha era fina o suficiente para promover um merge, uma fusão entre corpo e artefato, realçando e tornando ainda mais sinuosos os corpos das moças em dança, que repetiam movimentos circulares.

Havendo desvendado essa lógica, voltei a campo, dessa vez tendo como contexto de investigação a rede de relações de Mr. Catra. Meus sentidos estavam em busca de outras discussões, e foi ao esquecer a calça e as roupas feminina e masculina, no sentido de não tê-las como foco central de minha atenção, que os cabelos me argolaram, ao mesmo tempo em que trouxeram de volta a calça. Pois parece ter sido o próprio processo de seu esquecimento que me fez ver os cabelos e entender que a calça não aparecia no novo contexto de investigação não tanto por não estar mais tão em voga, mas porque confirmava o que os cabelos estavam me dizendo: que eles estendiam as pessoas, agiam em sintonia com seu desejo de conectividade. A calça, por sua vez, localiza as usuárias, cristaliza sua identidade funkeira, operação que era precisamente o que todas aquelas mulheres buscavam evitar. Escapar não ao funk, mas a uma noção de identidade concebida como categoria que atrela as identidades individuais a algum traço saliente comum, como o grupo ou a etnia. Em vez de circunscrever a pessoa, os cabelos a magnificam, levam-na pela cidade, que era o que interessava agora, mais do que dançar.

Resolvi olhar mais de perto o processo de produção dos cabelos, sua retirada, colocação, e o "relaxamento" das raízes entre uma e outra etapa. Fiz isso acompanhando Célia e Tábata que, talvez para se diferenciar da madrasta, resolveu que trataria de seus cabelos não com Taninha, que vinha até sua casa, mas em um salão em Madureira, distante uma hora e ao qual fomos diversas vezes em meu carro. Quando eu não as podia acompanhar, elas seguiam de ônibus. As produções dos cabelos foram contudo acompanhadas das produções por todo o corpo. 


\section{O CORPO COMO SUJEITO}

Minha primeira ida à Madureira com Célia e Tábata foi quase por acaso. Eu chegara à casa em uma tarde seguinte a uma noitada pós-“puteiro", e os músicos no estúdio estavam todos "derrotados". Catra, já acostumado com o ritmo da vida funk, como disse Sílvia, era o único que "estava para a rua". Sílvia, tomada pelo mau humor que a cercou no início de sua gravidez, também não estava muito interessada em conversar comigo, e Célia e Tábata se arrumavam para sair. Decido então ir embora e aproveitar o restante da tarde para resolver algumas pendências. Antes de sair, acompanho a conversa delas com Kátia, a faxineira, que dizia haver "domado", alisado, seus cabelos no dia anterior. Tábata diz que seu cabelo é "duro" e que não pode usar o "creme alisante" de Kátia, pois ele "cairia". Pergunto a Tábata se posso tocar seus cabelos, e ela diz que sim. Eu acho seu toque macio, gostoso, e falo isso a ela, que ri, dizendo "não é nada".

Sílvia sugere então que as moças sigam comigo e que eu as deixe em algum lugar ao longo de meu trajeto. Eu digo "ok" e acrescento que irei até o Leblon. E Sílvia responde com sarcasmo: "não adianta nada oferecer carona até o Leblon para quem vai para Madureira". Pensando retrospectivamente, aquele parece ter sido um modo seu de me colocar na direção dos cabelos, o mesmo modo indireto e não explícito que muitas vezes pauta as comunicações verbais naquele ambiente. Pois ocorre que em seguida lamento comigo mesma deixálas a meio caminho e penso que, afinal de contas, aquela poderia ser uma boa oportunidade para acompanhar mais de perto a produção dos cabelos. Resolvo, então, ir com elas.

Célia vestirá microssaia jeans da ACR e blusa roxa baby look, um tipo de $t$-shirt curta e ajustada ao corpo, da Puma, com o contorno da pantera, a logomarca da empresa, gravada em cristal sobre a parte frontal da blusa. Tábata também vestirá uma baby look da Puma, vermelha, com a pantera estampada por vinil fotorrefletor no alto do peito e na lateral da manga de um dos ombros da blusa, e calça jeans capri, de comprimento acima do tornozelo, da Abusiva que, ela diz, não é marca de funkeira. Já a ACR, patrocina festas funk, como as noites de quinta-feira, dedicadas ao ritmo, na Via Show, casa de espetáculos localizada na Rodovia Presidente Dutra, na altura de São João de Meriti, área periférica do Rio. Essas roupas começaram sendo vendidas por sacoleiras nas favelas cariocas e, ao longo do trabalho de campo, desenvolveram seu alcance. O hit da marca eram então as "sainhas" jeans supercurtas e sem qualquer elasticidade, soltas no quadril, como as que Célia vestiria. 
Figura 5: Jeans com elastano

Foto de Mylene Mizrahi

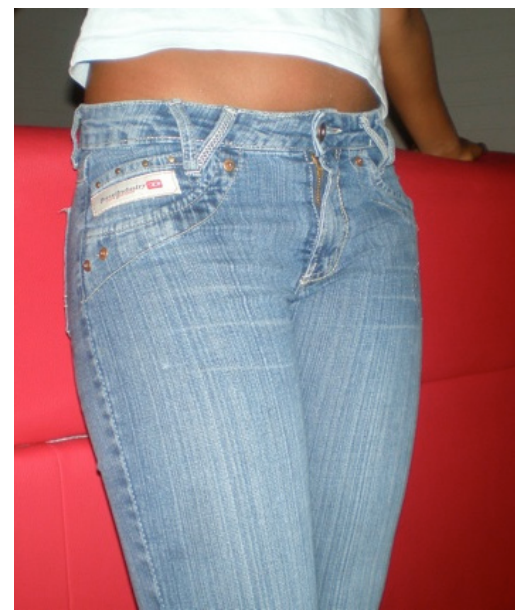

As mulheres produzem sua moda, como objetificado pela "calça de moletom stretch" (Figura 5), e também as próprias marcas. Além da ACR, muito presente durante o trabalho de campo do doutorado foi a M\&M, que faz blusas e tops em malha elástica e sintética, sempre adornadas por brilhos, como nas roupas da PXC de Cíntia e de Lucia e como presente na "calça de moletom stretch". Essas blusas custavam entre cinco e 20 reais, e eram vendidas de porta em porta, em pequenas lojas e nas feirinhas. E mesmo que usem marcas globais, o corpo determinará a sua modelagem.

Em outra tarde em que saíamos para o salão em Madureira, Tábata vestia uma calça jeans bem justa, certamente com elastano na composição do tecido, em índigo blue bem leve e fino, produzindo efeito similar de fusão com o corpo como o moletom stretch produz, realçando as formas corporais. Pergunto-lhe onde comprou a peça de roupa, e ela responde que comprou em São Paulo, acrescentando que é da Diesel, em tom que me pergunta se eu não percebia isso. A calça parece ser uma 'réplica' da marca estrangeira, mas que resulta de lógica interessante: reproduz a marca apenas, mas não a modelagem, que é desenvolvida de modo a atender ao gosto local. Essa particularidade do gosto feminino não apenas de produzir sua própria moda, mas de englobar através do corpo a marca e o gosto globais, foi-me posteriormente confirmada pelo próprio Mr. Catra. A propósito das roupas que Cíntia e Sílvia vendiam para a sua rede de relações na favela, ele diz que aquelas direcionadas para as mulheres nada mais são do que "cópias das nossas roupas com as marcas deles". A modelagem é nossa, a marca é dos "gringos". Não há aqui um protótipo único, mas dois, que em relação originaram uma terceira coisa. 
Os "gringos", como também Cíntia mencionou ao descrever a cor de sua pele, não são apenas os estrangeiros não brasileiros, mas aqueles que não possuem vínculo com a favela. Assim, as marcas copiadas podem ser as italianas Dolce \& Gabbana e Diesel, a alemã Puma, mas também as paulistanas Carmin e Cavalera. Se com a roupa masculina, continua Catra, "eles", os estrangeiros, "partem na frente", no que diz respeito à roupa feminina, "o Brasil dita a moda". Se na música funk o beat é soberano e a ele submete as inovações feitas, quanto à indumentária das moças, o que a conduz é o corpo. O gosto global precisa submeter-se a suas vontades. Essa mesma lógica produziu a "calça de moletom stretch", uma solução criada em terras brasileiras para o global jeans a partir das exigências da corporalidade local.

\section{A PRODUÇÃO DOS CABELOS E A NOÇÃO DE PESSOA}

Cerca de 50 minutos depois chegamos a Madureira. Vamos em direção ao salão de cabeleireiros, mas antes entramos em uma loja que vende cabelos. Nos dirigimos ao display que expõe os cabelos anelados e pretos. Na parede oposta estão os cabelos loiros, vermelhos e marrons, e também outros pretos. Parecem ser mais lisos do que os que estão do outro lado. Célia é atraída pelo cabelo loiro. Toca-o e diz que quando comprar os seus serão daquele tipo, mais "macio", mas os tingirá de preto. O aspecto loiro dos cabelos despertou em Célia interesse por eles, que em seguida avaliou sua materialidade e notou como eram agradáveis ao toque. Por fim, considerou a possibilidade de incorporá-los ao seu gosto. O que moveu Célia foi a oportunidade que vislumbrou de realizar a mesma operação englobadora que rege a estética funk como um todo, resultante de estratégias miméticas de se relacionar com a alteridade, no sentido de Taussig (1993), "domesticando", tornando familiar e trazendo para o interior do socius, o outro desconhecido ou ameaçador, modelo recorrente em sociedades amazônicas (LAGROU, 1998, 2007, 2009; GUSS, 1990; ALBERT, 2002; BUCHILLET, 2002; HOWARD, 2002; VAN VELTHEM, 1992).

Entramos em um prédio pequeno e simples. No primeiro andar há um consultório dentário. Subimos as escadas estreitas e pouco iluminadas que contrastam com o interior muito amplo e claro do salão de cabeleireiro, decorado em branco, azul-celeste e azulão. Célia exclama: "chegamos ao paraíso". Suponho que seu bem-estar talvez fosse causado pelo frescor que o ar-condicionado produzia no ambiente, mas sua felicidade é porque terá seus cabelos tratados. Ela paga ao entrar e Tábata desembolsa um pouco mais do 


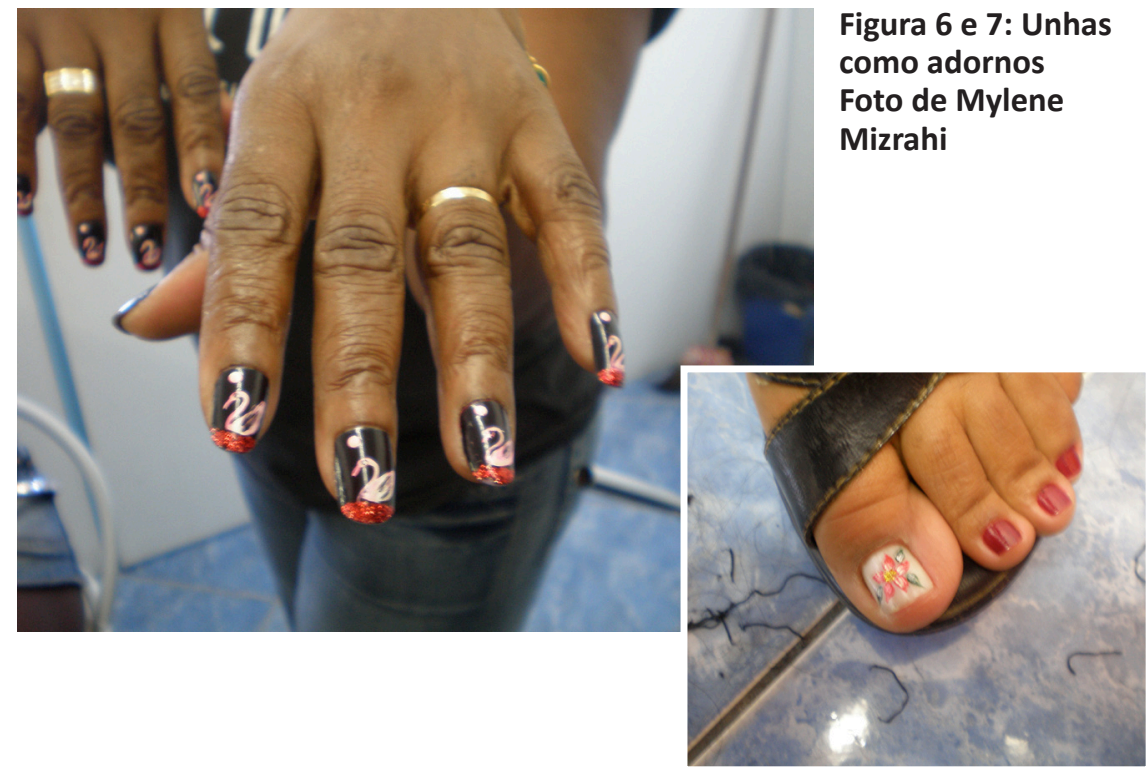

que o dobro do valor pago por Célia. Tábata terá os seus apliques removidos e prefere fazer isso na privacidade de uma "sala VIP".

Aguardamos para que iniciem o relaxamento que será feito nos cabelos de Célia, que me conta que os fios que dão mais trabalhos são os que circundam o rosto, os "parentes". Eu repito o termo, mostrando que não entendi, e Tábata ri, dizendo ser esse o nome dado aos fios de cabelo da parte frontal do couro cabeludo. E Célia traduz a metáfora: "são como parentes, você não escolhe: bom ou ruim, você tem que aturar". Célia pergunta a Tábata se aqueles cabelos que tirará irão para Tina ou para ela, e Tábata diz que irão para Tina. Célia diz que está "tudo bem". Quando chegar a sua vez de receber os cabelos de Tábata, o que ocorreria em três meses, seus cabelos já estarão tratados pelo relaxamento.

Procuro entender melhor o tipo de cabelo que Ihes agrada. Tábata diz que gostariam de ter um cabelo "liso", e olha para o meu e fala, "não tão liso assim", mas que enrole. Célia diz que se tivesse que pedir algo pediria "um novo couro capilar". Eu já havia escutado comentário similar de Tábata que, na tarde em que assistíamos à novela com Tina e Sílvia, disse que gostaria de ser uma "cientista para inventar uma fórmula para mudar o couro cabeludo". Inventaria uma cirurgia para trocar o couro por um que permitisse nascer um novo fio de cabelo. Sílvia se engaja em seu voo imaginativo e diz que "não, cirurgia dói muito" e na cabeça é "perigoso". Ela, diz, inventaria uma injeção. Seriam 
três aplicações. A primeira para preparar... Tábata a interrompe, insistindo na cirurgia, pois se existe para colocar silicone nos seios, para diminuir a gordura e a flacidez, por que não uma para "melhorar o cabelo?!".

Subimos para o segundo andar, onde ficam as pequenas salas individuais. Na sala destinada a Tábata há uma antiga e pequena televisão. Sentada em uma cadeira, ela tem as suas mechas retiradas por Renata, que corta com uma tesourinha o fino elástico que as prende aos fios de cabelo originais da moça. Tábata diz que já imagina o desespero que será para desembaraçar o seu cabelo. Joana, outra profissional, entra para falar que será ela quem fará o relaxamento no cabelo de Tábata, após a retirada das extensões. Joana tem as unhas das mãos decoradas por esmalte com um minicisne meticulosamente desenhado em rosa, nadando sobre um lago vermelho - a ponta de sua "unha francesinha" - sob a lua cheia e contra um fundo escuro, como é a noite (Figura 6). Eu fico fascinada pelo trabalho e seu preciosismo. Quero fotografar, mas Célia me alerta, lembrando que na última vez em que lá estivemos me disseram que eu não poderia fazê-lo. Joana diz que não se preocupa com isso, argumentando que as unhas lhes pertencem e que eu posso sim fotografá-las. Renata aproveita para me mostrar a decoração na unha do dedo grande de seu pé, uma flor, motivo menos incomum, mas ainda assim feito de modo bastante elaborado (Figura 7).

Renata me explica que de fato "o modo de uma negra se arrumar é totalmente diferente do de uma branca". Elas, diz, são como que "montadas", e é nesse montar que começará a emergir mais claramente a noção de pessoa que as diferencia das "brancas", as que não precisam "sofrer para ficar bonita". A corporalidade é relevante como em contexto ameríndio (SEEGER, DAMATTA; VIVEIROS DE CASTRO, 1987), mas, diferentemente do que ali ocorre, o que parece conceder a perspectiva do sujeito não é tanto o que é ingerido e diluído internamente, produzindo os afetos (VIVEIROS DE CASTRO, 1996), mas a aparência e o que lhe é adicionado, o que é acrescentado à superfície do corpo. Dessa perspectiva, o modo como a exterioridade é relevante para a definição da noção de pessoa num contexto funk é mais próximo do contexto caribenho (MILLER, 1994).

No entanto, não são apenas as transformações na aparência que definem a pessoa, mas também uma capacidade que parece ser congênita ao corpo, inata, que é categorizada por meio da aparência. A aparência e as elaborações a seu respeito, como ficará mais claro ao longo da narrativa, confirmam as capacidades do corpo não branco. Dessa perspectiva, as modificações na aparência de Cíntia não ocorrem em continuidade com transformações em 
seus afetos, causados pelo convívio e hábitos alimentares estabelecidos em um modo de vida outro, como ocorre com a jovem Yanesha, que passa a viver na cidade e adquire modos e costumes "brancos" (SANTOS-GRANERO, 2009). No funk não há tal cisão clara entre mundos, e Cíntia, ao parecer branca, se utiliza da ambiguidade de sua aparência deliberadamente como meio de se empoderar do poder do outro através da mimésis, se transpondo corporeamente para sua imagem (TAUSSIG, 1993, p. 40). Cíntia, ao "vestir uma roupa-máscara", não oculta ou altera sua essência, mas o faz de modo a "ativar os poderes de um corpo outro" (VIVEIROS DE CASTRO 1996, p. 133).

Renata diz que nós, as brancas, não temos a "resistência" que elas têm, e que eu não imagino o quanto elas sofrem para ficar bonitas. Nós não temos resistência para colocar cabelo e unha do modo que elas fazem, pois, de acordo com Renata, somos mais "meiguinhas", delicadas. Tábata, em outro momento e a propósito de uma leve dificuldade de movimento que tivera com seus lábios, disse-me que ela é atípica, pois "apesar de negra é cheia de frescuras". Observo que não é por ser negra que não pode ser "fresca", mas ela insiste, argumentando que seu pai afirma que o negro tem anticorpos mais resistentes, e ela tem muita alergia a poeira e a mordida de mosquito, e "agora isso", "não pode tomar golpe de ar frio", evento que supostamente lhe teria causado o incômodo na face.

Os cabelos nos fazem ver ainda outra importante associação, aquela que vincula beleza a ganho monetário e poder aquisitivo. Tina começou a colocar cabelo ao trabalhar com Sílvia, mas lamentava o fato de estar desempregada naquele momento. Havia a promessa de uma faxina, que lhe renderia 150 reais. Já sabia o que faria com o dinheiro. Cem reais usaria para colocar os cabelos que herdaria de Tábata, e com os 50 restantes compraris comida para o filho e outras coisas de que ele necessitava na prisão. Célia diz que fica "triste" se não puder "tratar" os cabelos, e por isso dá "graças a Deus" por ter "esse emprego": "A tristeza da minha vida é quando eu estou com esses cabelos duros. Pode faltar tudo, comida para comer, roupa para vestir...". Sem cuidar de seu cabelos ela não pode ficar: "fico com vergonha, não saio". A cabeleireira penteia os cabelos de Célia, passando-Ihes "creme de pentear", próprio para serem aplicados após lavados e enxaguados. Ela diz que o cabelo de Célia está "quebrando muito", e recomenda que ela use ampolas de vitamina A e D. Célia fala, animada, que não se importa que seu cabelo esteja "quebrando", pois comprará a ampola, e seu cabelo ficará "dez". Ela se levanta e anda em direção a um grande espelho. Vai rebolando, com as nádegas empinadas e gingando o corpo, e fala que fará "sucesso" com "os novinho" de onde mora. 
Em breve, diz, sua "bunda", que chamaram de "murcha", e sua "canela", que disseram ser "fina", estarão "cheias", graças, também, ao emprego que Deus lhe providenciou.

\section{A LÓGICA DA PRÓTESE}

Os cabelos informam sobre uma noção de pessoa que é específica, ao mostrar sua diferença em relação ao "jeito" de ser do "branco", e, simultaneamente, desestabiliza uma concepção de identidade negra fixa. Em pesquisa realizada em "salões étnicos" da cidade de Belo Horizonte, rótulo que parecia ser evitado por Tábata e Célia, Nilma Lino Gomes (2006, p. 144) defende que o aspecto político que poderia residir nos processos de embelezamento estará sempre presente, posto que, "por mais intervenções estéticas que realizem, esses "sujeitos sabem que, mesmo apresentandose alisado, pranchado ou alongado, seu cabelo sempre será crespo e sempre remeterá à raça negra". Entre Cíntia, Tábata, Célia, Regina e Tina não se nota tal cisão, como se houvesse uma essência que a aparência estivesse a camuflar. Tampouco existe alguma instância outra a se "remeter" que não a comunicada pela própria aparência física, antes ou depois das ações embelezadoras. Não emerge dos seus discursos, orais e corporais, o desejo de se fazer "passar por" branca. Ao contrário, desde o princípio o que se afirma é a diferença, e as ações embelezadoras não surgem para camuflar ou minimizar essa diferença, mas para reinscrevê-la de um modo que atenda a seu gosto. Pois se os cabelos eleitos para alongar as mechas originais não são nunca lisos, mas sempre anelados, é por desprezarem também uma época em que as possibilidades de embelezamento eram restritas. Longos ou curtos, lisos ou crespos, estendidos ou não, os cabelos precisam "sempre" ser tratados.

Peter Fry (2002, p. 323), ao abordar cabeleireiros 'étnicos' e mercado dos produtos de beleza para negros, chama atenção para o potencial político que a "preocupação individual com a aparência" pode conter. Apontando forte correspondência entre aparência e inner self, considera que as mudanças de representação e autoapresentação podem contribuir para a erradicação da discriminação e da desigualdade e gerar "sociabilidade intensa" que leve à "formação de uma identidade 'negra' coletiva que pode ir além do interesse comum de produzir beleza" (p. 324). Os cabelos resultam também de um consumo conspícuo, no sentido de Thorstein Veblen (1983). Ao contrário, porém, de a conspicuidade dos objetos indicar o ócio, ela enfatiza o valor atribuído ao trabalho. 
Não se trata, entretanto, apenas de conceder uma prova visual de felicidade e da igualdade alcançada (BAUDRILLARD apud CRARY, 1990, p. 11). O consumo ostentatório, mais evidente por meio do gasto que envolve a compra e a colocação das longuíssimas extensões de Sílvia e Tábata, aproxima-as menos de classes hierarquicamente superiores, do que do movimento de diferenciação e criação de modas como empreendeu a emergente burguesia ao buscar inserção e visibilidade na sociedade de corte francesa (ELIAS, 2001). Não se quer aqui tanto passar por "branca", mas tampouco permanecer com um cabelo que, entendem, as localiza em um lugar da falta e da ausência. Daí os cabelos serem muitas vezes conspicuamente longos, pois devem desfazer uma imagem da escassez, distanciando-as de um "gosto da necessidade" (BOURDIEU, 1984).

O que, no entanto, une essas moças todas não é tanto o cabelo, mas a lógica da prótese e da transformabilidade que esses cabelos evidenciam, pois a mesma plasticidade que vimos no colocar e retirar cabelos vimos também nas unhas postiças de Joana, cujo uso visa não necessariamente encobrir unhas feias ou fracas. As unhas de Sílvia, por exemplo, sempre chamaram a minha atenção quando, em fase de troca, eu podia ver que as originais eram longas e fortes. Não se trata, tampouco, de um consumo puramente ostentatório, pois a mesma Joana das unhas postiças possui suas curtas mechas há 13 anos.

Falamos da produção de uma estética corporal segundo a qual a beleza não é tanto dada como feita. A beleza no funk não é produzida para se transformar no outro, como nota Sonia Maluf (2002) para o transgênero, mas está igualmente ligada ao "caráter artificial e fabricado" (p. 148) do corpo na definição, em meu contexto de estudo, do feminino. O manipular do corpo obedece à ideia de que ele é resistente às intervenções que lhe são feitas. A hipotética cirurgia que Tábata sugeriu fez coro, assim, com outras não fictícias que davam conta de dentes extraídos ou implantados, seios e nádegas colocados, lipoaspirações realizadas.

As efígies, canoas, lanças, ou o que for, são ao mesmo tempo da pessoa e mais do que a pessoa. Não se trata de que sejam apenas extensões integrais às relações que uma pessoa estabelece, e "instrumentos" nesse sentido, mas de que o corpo físico é apreendido como composto desses instrumentos como é composto de relações (STRATHERN 2004, p. 76).

As próteses aqui estendem a pessoa e, se são "extensões do corpo" (SANTOS-GRANERO, 2009, p. 486), não são por isso apreendidas como "partes extrassomáticas" desse corpo (ERIKSON apud SANTOS-GRANERO, 2009, p. 486). Se aumentam a mobilidade do self, são também dele constitutivas, pois, se os cabelos implantados são preferencialmente anelados, escolher sua coloração 
passa também por uma adequação à cor da pele, como vi em Regina que, ao manusear as mechas que seriam posteriormente colocadas, dizia que as tingiria primeiro, acrescentando que "o meu cabelo não é dessa cor", da cor que as mechas compradas apresentavam originalmente. E o cabelo, como disse Catra, "depois que você [o] colocou é seu, filha". O corpo é artefatual, mas as próteses fazem ver não seu aspecto não humano, mas sua fusão com o corpo, sua absorção por ele.

\section{$* * *$}

Sento-me à mesa de jantar, onde Taninha faz os cabelos de Tânia, filha que Catra tomou como sua, mas nascida de uma ex-mulher com outro homem. Taninha mistura três diferentes tonalidades de cabelos na cabeça de Tânia. E diz que foi a moça que "inventou isso". De início ela só usaria os cabelos herdados de Regina, que são de tom acobreado e casam também com a pele de Tânia. Mas Tânia comprou ainda mechas pretas e outras marrons. O efeito estava ficando bastante interessante, e pensei que aquele era um modo diferente de tingir cabelos. Era como um jogo, em que o encaixe das diferentes colorações de cabelo permitia que se tivesse uma visualização antecipada do resultado a que se planejara chegar.

Taninha diz que as extensões, o mega hair, "fez com que os negros pegassem os papéis principais". Refere-se às produções da TV Globo e, em especial, a Viver a Vida, novela que ia ao ar no chamado "horário nobre" e que tinha como personagem principal a atriz Thaís Araujo. Era a primeira vez que um ator negro ocupava tal posição. Taninha diz que ao colocarem os cabelos "já não são mais negros". Eu continuo a escutá-la: "São morenos, mulatos... Mas não negros".

Taninha segue falando sobre as angolanas que atende e me pergunta se Angola fica perto. Eu lhe repondo negativamente, dizendo que existe, entretanto, uma rota de "sacoleiras" que parte de Angola para comprar roupas no Brasil que serão revendidas em seus países de origem. Ela explica que diferentemente das brasileiras, as angolanas querem cabelos o mais liso possível. Alisam o cabelo e ainda passam prancha, conta, acrescentando que elas não molham o cabelo sob qualquer hipótese, como faz ao trabalhar as mechas na cabeça de Tânia. Separa com uma pinça de alumínio o pequeno tufo de cabelo desde a raiz do couro cabeludo e o umedece com um borrifador de água. Taninha diz que "aqui" todo mundo quer poder molhar o cabelo e quer cabelos anelados. Acredita que as angolanas, por terem "o cabelo tão duro", 
querem-nos lisos a todo custo. Com a novela, prevê, ao verem os cabelos da personagem principal - longos, fartos e anelados - essa tendência deve mudar.

As mulheres funk não apenas fazem a própria moda como a disseminam pelo mundo e distribuem, assim, sua agência. Taninha reafirmou, nessa breve conversa que tivemos em meu retorno ao campo, o poder que os objetos possuem de transportar as pessoas, de as deslocar, de levá-las para outros domínios.

\section{REFERÊNCIAS BIBLIOGRÁFICAS}

ALBERT, Bruce. O ouro canibal e a queda do céu: uma crítica xamânica da economia política da natureza (Yanomami). In: ALBERT, Bruce; RAMOS, Alcida Rita (eds.). Pacificando o branco: cosmologias do contato no norte amazônico. São Paulo: Editora Unesp. 2002.

BOURDIEU, Pierre. Distinction. London: Routledge and Kegan Paul. 1984.

BUCHILLET, Dominique. Contas de vidro, enfeites de branco e 'potes de malária': epidemiologia e representações de doenças infecciosas entre os Desana do alto Rio Negro. In: ALBERT, Bruce; RAMOS, Alcida Rita (eds.). Pacificando o branco: cosmologias do contato no norte amazônico. São Paulo: Editora Unesp. 2002.

CRARY, Jonathan. Modernity and the problem of the observer. In:

Techniques of the observer: on vision and modernity in the nineteenth century. Cambridge/London: MIT Press. 1990.

ELIAS, Norbert. A sociedade de corte: investigação sobre a sociologia da realeza e da aristocracia de corte. Rio de Janeiro: Jorge Zahar Editor, 2001.

FRY, Peter. Estética e política: relações entre 'raça', publicidade e produção de beleza no Brasil. In: GOLDENBERG, M. (org.). Nu e vestido. Rio de Janeiro: Record. 2002.

GOMES, Nilma Lino. Sem perder a raiz: corpo e cabelo como símbolos da identidade negra. Belo Horizonte: Autêntica. 2006.

GUSS, David. To weave and sing: art, symbol and narrative in the South American Rain Forest. Berkeley: University of California Press, 1990

HOWARD, Catherine V. A domesticação das mercadorias: estratégias Waiwai. In: ALBERT, Bruce; RAMOS, Alcida Rita (eds.). Pacificando o branco: cosmologias do contato no norte amazônico. São Paulo: Editora Unesp. 2002.

LAGROU, Els. Caminhos, duplos e corpos: uma abordagem perspectiva da identidade e alteridade entre os Kaxinauá. Tese (doutorado), University of St. Andrews/USP, Scotland/São Paulo. 1998.

. A fluidez da forma. Arte, alteridade e agência em uma sociedade amazônica (Kaxinawa, Acre). Rio de Janeiro: Topbooks. 2007. 
A arte das sociedades contra o estado. Trabalho apresentado no Sesc-São Paulo. Colóquio Pierre Clastres: pensar a política à contracorrente. São Paulo, 6 a 9 de outubro de 2009.

MALUF, Sônia Weidner. Corporalidade e desejo: Tudo sobre minha mãe e o gênero na margem. Estudos Feministas. n. 10, v.1. 2002.

MILLER, Daniel. Modernity: an ethnographic approach: dualism and mass consumption in Trinidad. Oxford/New York: Berg. 1994.

MIZRAHI, Mylene. A influência dos subúrbios na moda da Zona Sul. Monografia (pesquisa coordenada para a Universidade Estácio de Sá). Rio de Janeiro. 2003.

. Figurino funk: uma etnografia sobre roupa, corpo e dança em uma festa carioca. Dissertação (mestrado), Programa de Pós-Graduação em Sociologia e Antropologia, Universidade Federal do Rio de Janeiro. Rio de Janeiro. 2006.

. A estética funk carioca: criação e conectividade em Mr. Catra. Tese (doutorado), Programa de Pós-Graduação em Sociologia e Antropologia, Universidade Federal do Rio de Janeiro. Rio de Janeiro, 2010.

SANTOS-GRANERO, Fernando. Hybrid bodyscapes: a visual history of Yanesha patterns of cultural change. Current Anthropology. v. 50, n. 4. 2009.

SEEGER, Anthony, DAMATTA, Roberto; VIVEIROS DE CASTRO, Eduardo. [1979]. A construção da pessoa nas sociedades indígenas brasileiras. In: OLIVEIRA FILHO, J. P. Sociedades indígenas e indigenismo no Brasil. Rio de Janeiro: UFRJ/Marco Zero. 1987.

STRATHERN, Marilyn. [1991] Partial connections. Lanham, Maryland: Altamira Press, 2004.

TAUSSIG, Michael. Mymesis and alterity: A particular history of the senses. London: Routledge. 1993.

VAN VELTHEM, Lucia. Das cobras e lagartas: a iconografia wayana. In: VIDAL, L. (org.). Grafismo indígena: estudos de antropologia estética. Sao Paulo: Studio Nobel/Editora da Universidade de Sao Paulo/Fapesp, 1992.

VEBLEN, Thorstein. A teoria da classe ociosa: um estudo econômico das instituições. São Paulo: Abril Cultural. 1983.

VIVEIROS DE CASTRO, Eduardo. Os pronomes cosmológicos do perspectivismo ameríndio. Mana. Rio de Janeiro, v. 2, n. 2. 1996.

Mylene Mizrahi é doutora em antropologia cultural pelo PPGSA-IFCS-UFRJ e pós-doutora na mesma instituição. 
